\title{
Not genetically inherited
}

INSERM

\section{Source}

INSERM. (1999). Orphanet: an online rare disease and orphan drug data base. not genetically inherited. ORPHA:409941

clinical entity without genetic inheritance. 